Original article

\title{
Fighting obesity: Non-pharmacological interventions
}

\author{
María Fernanda Higuera-Hernández a, b, c, Elena Reyes-Cuapio ${ }^{\text {a, b, c }}$, \\ Marissa Gutiérrez-Mendoza ${ }^{\mathrm{a}, \mathrm{c}}$, Nuno Barbosa Rocha ${ }^{\mathrm{c}, \mathrm{d}}$, André Barciela Veras ${ }^{\mathrm{c}, \mathrm{e}}$, \\ Henning Budde ${ }^{c, f, g, h, i}$, Johanna Jesse ${ }^{\mathrm{f}}$, Jaime Zaldívar-Rae ${ }^{\mathrm{j}}$, Carlos Blanco-Centurión ${ }^{\mathrm{k}}$, \\ Sérgio Machado ${ }^{\mathrm{c}, \mathrm{l}, \mathrm{m}}$, Eric Murillo-Rodríguez ${ }^{\mathrm{a}, \mathrm{b}, \mathrm{c}, \text { * }}$ \\ ${ }^{a}$ Laboratorio de Neurociencias Moleculares e Integrativas, Escuela de Medicina, División Ciencias de la Salud, Universidad Anáhuac Mayab, Mérida, \\ Yucatán, Mexico \\ ${ }^{\mathrm{b}}$ Escuela de Nutrición, División Ciencias de la Salud, Universidad Anáhuac Mayab, Mérida, Yucatán, Mexico \\ c Intercontinental Neuroscience Research Group, Mexico \\ ${ }^{\mathrm{d}}$ Faculty of Health Sciences, Polytechnic Institute of Porto, Porto, Portugal \\ e Dom Bosco Catholic, University, Campo Grande, Mato Grosso del Sur, Brazil \\ ${ }^{\mathrm{f}}$ Faculty of Human Sciences, Medical School Hamburg, Hamburg, Germany \\ ${ }^{g}$ Physical Activity, Physical Education, Health and Sport Research Centre (PAPESH), Sports Science Department, School of Science and Engineering, Iceland \\ ${ }^{\mathrm{h}}$ Reykjavik University, Reykjavik, Iceland \\ ${ }^{\mathrm{i}}$ Lithuanian Sports University, Kaunas, Lithuania \\ j Vicerrectoría Académica, Universidad Anáhuac Mayab, Mérida, Yucatán, Mexico \\ k Department of Psychiatry and Behavioral Sciences, The Medical University of South Carolina, Charleston, SC, USA \\ ${ }^{1}$ Laboratory of Panic and Respiration, Institute of Psychiatry, Federal University of Rio de Janeiro, Rio de Janeiro, Brazil \\ $\mathrm{m}$ Physical Activity Neuroscience Laboratory, Physical Activity Sciences Postgraduate Program of Salgado de Oliveira University, Niterói, Brazil
}

\section{A R T I C L E I N F O}

\section{Article history:}

Received 8 August 2017

Accepted 2 April 2018

\section{Keywords:}

Obesity

Diets

Therapy

Weight

Physical activity

Intervention

\begin{abstract}
S U M M A R Y
The abnormal or excessive fat accumulation that impairs health is one of the criteria that fulfills obesity. According to epidemiological data, obesity has become a worldwide public health problem that in turn would trigger additional pathologies such as cardiorespiratory dysfunctions, cancer, gastrointestinal disturbances, depression, sleep disorders, just to mention a few. Then, the search for a therapeutical intervention aimed to prevent and manage obesity has been the focus of study during the last years. As one can assume, the increased prevalence of obesity has translated to search of efficient pharmaceuticals designed to manage this health issue. However, to further complicate the scenario, scientific literature has described that obesity is the result of interaction between multiple events. Therefore, pharmacological approaches have faced a serious challenge for develop the adequate treatment. Here, we argue that a wide range of non-pharmacological/invasive techniques can be used to manage obesity, such as diets, cognitive behavioral interventions, exercise and transcranial direct current stimulation. Combining these techniques may allow improving quality of life of obese patients.
\end{abstract}

๑) 2018 European Society for Clinical Nutrition and Metabolism. Published by Elsevier Ltd. All rights reserved.

\section{Introduction}

Obesity is health world-wide problem that has been defined as excessive accumulation of fat in the body. Classification of normal, overweight or obese patients include several anthropometric

\footnotetext{
* Corresponding author. Laboratorio de Neurociencias Moleculares e Integrativas, Escuela de Medicina, División Ciencias de la Salud, Universidad Anáhuac Mayab, Carretera Mérida-Progreso Km. 15.5, A.P. 96 Cordemex, C.P. 97310, Mérida, Yucatán, Mexico.

E-mail address: eric.murillo@anahuac.mx (E. Murillo-Rodríguez).
}

criteria, such as body mass index (BMI) which categorizes patients as obese if this anthropometric measurement is greater than $30 \mathrm{~kg} / \mathrm{m}^{2}$ (Fig. 1) [1].

In addition, it has been reported that obesity is considered as an epidemy in several countries, including the United States of America [2-4] causing multiple health problems such as cancer, heart diseases, depression, sleep disorders, among other issues [5-8]. On the other hand, the etiology of obesity is complex and involves different elements such as diet, socioeconomic status, family influence, cultural aspects, lifestyle, etc [9-12]. For 


\section{DIFFERENT LEVELS OF OBESITY}

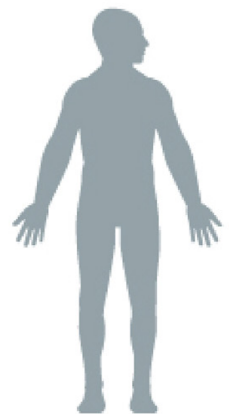

Normal Weight BMI: 18.5-24.9

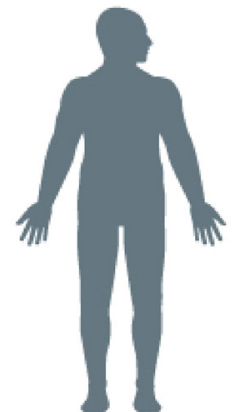

Overweight BMI: 25-29

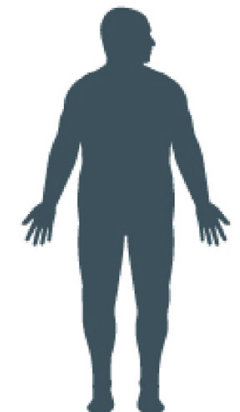

Obesity Level 1 BMI: $30-34.9$

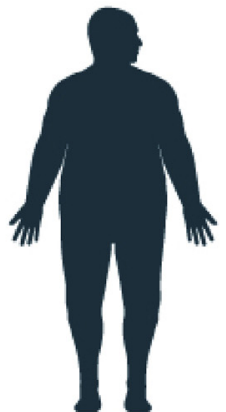

Obesity Level 2 BMI: 35-39.9

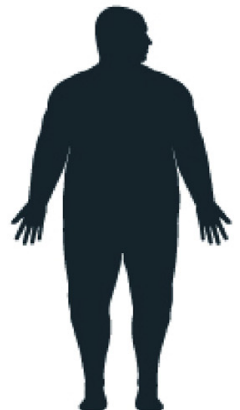

Obesity Level 3 BMl: $>40$

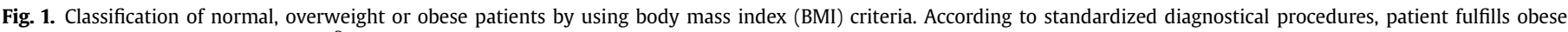
profile if BMI is greater than $30 \mathrm{~kg} / \mathrm{m}^{2}$.

example, in terms of biochemistry, recent reports have demonstrated that endocrine-disrupting compounds named "obesogens" are also linked to weight gain [13,14]. Moreover, gut microbiota has been suggested as a critical element in the development of obesity [15-17].

Taking together, the management of obesity requires a multidisciplinary approach. In the midst of a plethora of therapeutic intervention for obesity, pharmacological intervention is one of the most proposed approaches [18-21]. However, it has been demonstrated that many patients are still unable to reach clinically meaningful improvements. Thus, additional therapeutic interventions should be considered for preventive and modifiable obesity.

\section{Obesity}

Obesity is a medical condition that the World Health Organization defines as abnormal or excessive fat accumulation that may impair health [1]. Patients are generally considered obese when body mass index (BMI) is over $30 \mathrm{~kg} / \mathrm{m}^{2}$ [22]. Moreover, obesity is a risk factor for diabetes type 2, hypertension, dyslipidemia and other cardiovascular diseases, as well as cancer, obstructive sleep apnea and psychological problems, just to mention a few health disturbances $[23,24]$. The literature suggest that energy imbalance between calories consumed and calories expended plays a critical role in genesis of obesity as well as genetic or endocrine conditions and certain drugs also are linked with obesity [2].

\section{Non-pharmacological interventions for obesity}

\subsection{Diets}

Strategies to treat obesity have been focused on lifestyle significant modifications, including diets $[25,26]$. In this regard, diets enriched with vegetables and fruit consumption over a long-term period represent a positive outcome regarding health benefits [27-31]. However, several weight-management diets have limited positive results $[32,33]$.

\subsection{Cognitive-behavioral interventions against obesity}

Beyond identification of the multiple overlapping factors of obesity, one indisputable variable that contributes to the etiology of this disorder is the lifestyle [34,35]. Although is widely assumed that obesity might be addressed by solid foundations of healthy behaviors, healthy eating guidelines are in most of the cases unknown in general population [36]. As one can assume, the defiance for understanding the underpinnings of development of unhealthy behaviors will provide invaluable support for behavior interventions. By promoting health behaviors, such as choosing fruit and vegetables over processed foods, significant advances in behavior changes could be achieved. Several behavioral approaches have been effective for treating health issues, for example the Theory of Planned Behavior [37,38]. In this regard, Hamiltion and coworkers (2013) showed that according to this approach, elements which influence mothers' decisions about their child's adequate physical activity [34]. In sum, this intervention suggests that different roles of psychosocial factors exert critical relevance in mothers' decisions regarding their child engages in active lifestyle behaviors. The design of interventions aiming to reduce the consumption of unhealthy foods, apart from hypocaloric diets, should also promote health behaviors aimed to strengthen a balanced lifestyle.

\subsection{Exercise as treatment in obesity}

The recent findings conclude that physical exercise has significant effects on both physical and psychological health $[39,40]$. In this regard, physical exercise done voluntarily or being prescribed can be used as a treatment for obesity. Here, we would like to clarify some terms used in this review. Budde et al. [41] proposed definitions to differentiate physical activity from exercise and fitness. The terms "exercise"' and "training" are both defined as a structured, planned and repetitive progress to maintain or achieve physical fitness, although training is understood as a more chronic type of exercise [42]. The components that aim at the maintenance or achievement of physical fitness are related to health: For example, cardiorespiratory endurance or body composition, as well as strength and muscular flexibility [43]. Physical activity, in contrast, is defined as bodily movement which results in energy expenditure, but not with the goal of achieving or maintaining physical fitness [44].

The overall goal of exercise in the treatment or prevention of obesity is weight loss. To approach this goal, the Institute of Medicine of The National Academies of Science published the recommendation to undertake $60 \mathrm{~min}$ of moderate intensity 
exercise a day every day of the week without any change of caloric intake [45]. Similarly, The American College of Sports Medicine recommend exercise at a frequency of three to five times per week on $55 / 65 \%-90 \%$ of the maximum heart rate with $20-60 \mathrm{~min}$ of continuous or intermittent aerobic activity, but at least $150 \mathrm{~min}$ of aerobic exercise per week to develop and maintain a healthy lifestyle [46].

The physical benefits of an exercise training in obese patients are mainly described in a change in the metabolism, such as an improved liver function and hormone functions, like an increased insulin and leptin sensitivity as well as increased ghrelin levels [47-50]. Ghrelin has been shown to be a potent orexigenic hormone, which increases at the time of weight loss, which could explain the weight regain of obese patients after completing a strict dietary intervention [51-53]. The abovementioned hormones play a role in regulating satiety, hunger and energy balance and have shown to be regulated through exercise, for example within a 12month programme of dietary and exercise-induced weight loss. The researchers concluded that greater weight loss could be associated with increased ghrelin concentrations, but could not detect any difference in the exercise or dietary restriction group [54]. Further research emphasizes the need for further research, since most of the published studies concerning the metabolic effects of exercise have been conducted with healthy participants but less with obese patients, since the metabolic changes caused by exercise seem to be different in obese patients [55].

Another interesting question is the period for an exercise regimen to obtain the highest weight loss. Iwayama et al. [56] recommend completing an exercise intervention before breakfast, because the 24-h fat oxidation increases more when exercise is performed before breakfast, although the study was conducted with non-obese individuals. In contrast to this statement, a study on obese mice has shown more effective weight loss when exercise is undertaken at noon or in the evening in combination with energy intake before the exercise [57]. A possible combination of the abovementioned studies was published from Sasaki and coworkers [57], with high fat diet induced obese mice, in which the researchers propose that morning exercise could prevent obesity and evening exercise may counteract fat deposition. The contrary outcomes of the abovementioned studies implicate a need for further research, but all researchers concluded significant effects of exercise on obesity independent of the period.

On the other hand, Jakicic et al. [58] published a study to compare effects on different durations and intensities of aerobic exercise which endured for 12 months, and stated that the greatest impact on weight loss was achieved through a combination of a decrease of caloric intake and exercise. Since the main goal of an exercise treatment for obesity is weight loss, most studies comparing different exercise types, such as resistance or aerobic exercise, stated different outcomes, but all within a beneficial character for obesity symptoms [58-60]. Hence, we can conclude that it is not the mode of intervention, but the duration, which is of importance for a prolonged positive effect on the symptoms. Most research, however, suggests that a moderate intensity should be upheld. Lastly, Decker and Ekkekakis [61] compared the subjective felt pleasure and enjoyment of high-intensity interval exercise and moderate-intensity continuous exercise and stated that low-active obese women significantly preferred the moderate intense exercise form. This information is important for caregivers developing exercise programmes as a treatment form for obesity, to reduce the risk of dropout and ensure the compliance of obese patients. Even if a high intensity aerobic exercise could be more effective, the patient's compliance and subjective felt pleasure for the prescribed method could be of more importance for the positive outcome of an intervention [61].

\subsection{Transcranial direct current stimulation and obesity}

According to neuroimaging studies, obese subjects have an imbalance in the activity of pre-frontal and limbic circuits [62], corroborating data from studies that reported cognitive and reward brain mechanisms related to eating behavior [62-64]. Research in brain areas of obese patients indicates an abnormal activity in the left dorsolateral prefrontal cortex (DLPFC) involved in behavioral regulation, taste, and rewards processing [65-72]. In this regard, several studies have shown that obese patients undergoing treatment with satiated meal showed less activity in DLPFC compared to lean men [66-72]. It was also observed that obese women displayed less activation in the left DLPFC compared to lean and exobese women [69]. In addition, there were no differences in the brain activity of lean and ex-obese subjects, suggesting that the normalization of left DLPFC activity may occur after weight loss or there is a pre-existing endophenotype of subjects who are able to lose weight [72].

In this way, the manipulation of cerebral activity might be able to rebalance and translate it in beneficial behavioral changes, such as limiting the food intake [73]. Thus, new innovative approaches are necessary to promote behavioral changes, leading to successful weight loss, such as transcranial direct current stimulation (TDCS). This technique is a noninvasive neuromodulation methodology where a constant, low-intensity electrical current applied to the cortex through surface electrodes positioned on the scalp, with two different currents, anodal (excitatory) and cathodal (inhibitory) [74]. TDCS changes the spontaneous rates of neuronal discharge [75] by increasing or decreasing cortical excitability [76]. Its repeated application (i.e., consecutive days) may lead to long-term effects, resulting from synaptic changes involving the LTD and LTP process [53]. DLPFC plays an important role in the organization and planning of behavior [65]. Dysregulation of left DLPFC in obese subjects is likely to undermine regulation of dietary behavior and food choice, suggesting this region as a key target for obesity intervention. Experimental interventions in the left DLPFC could therefore add new understanding about this relationship, leading to new possibilities of treatments for weight loss [77].

Recently, several studies have revealed interesting findings stimulating DLPFC. For example, reports have shown reduced food craving [78-80], and food intake [81,82] after 1 or more tDCS sessions aimed at improving left [78-83] and right [80] DLPFC activity. However, none of these studies investigated the effect of tDCS directly on body weight loss, since only one session of tDCS was applied [78-83]. According to our knowledge, only two studies had longer duration than the other studies $[84,85]$. In a singleblind, randomized, placebo-controlled crossover study, Gluck and colleagues [84] examined the effects of anodal-tDCS applied to left DLPFC for $40 \mathrm{~min}$ at $2 \mathrm{~mA}$ on food consumption in overweight/ obeses subjects and found a significant decrease in food consumption (i.e., calories and fat) compared to cathodal-tDCS, but no effects compared to sham-tDCS. The second study investigated the effects of anodal-tDCS applied to right DLPFC on food cravings in obese subjects [85]. Anodal-tDCS was applied for five consecutive days at $2 \mathrm{~mA}$ during $20 \mathrm{~min}$, as well as sham-tDCS that included anodal-tDCS only in the first day followed by sham-tDCS. Authors found significant reduction in craving followed anodal-tDCS, but not to sham, and the reduction achieved remained for a full 25 days after the end of treatment.

The big challenge in obesity treatment is reach brain regions supporting eating behavior, which are located in deep brain zones. It is unclear whether tDCS could be reliability, sensitivity and specificity for deep areas [86]. tDCS is more useful for cortical areas, specially DLPFC, responsible for important cognitive functions, such as eating behavior. Future studies should examine in detail the 
specific prefrontal related processes that may underlie success in these subjects and, based on this information, design tDCS interventions to induce similar brain patterns in refractory obese subjects. This novel approach will likely require multiple sessions and high-intensity stimulation schemes, as long as safety is not compromised.

\section{Concluding remarks}

According to the World Health Organization, obesity is a pandemic issue [1]. It is acceptable that excessive energy intake that exceeds energy expenditure is one of the main causes of this disturbance. Multiple therapeutically strategies have been

\section{NON-PHARMACOLOGICAL INTERVENTIONS FOR OBESITY}

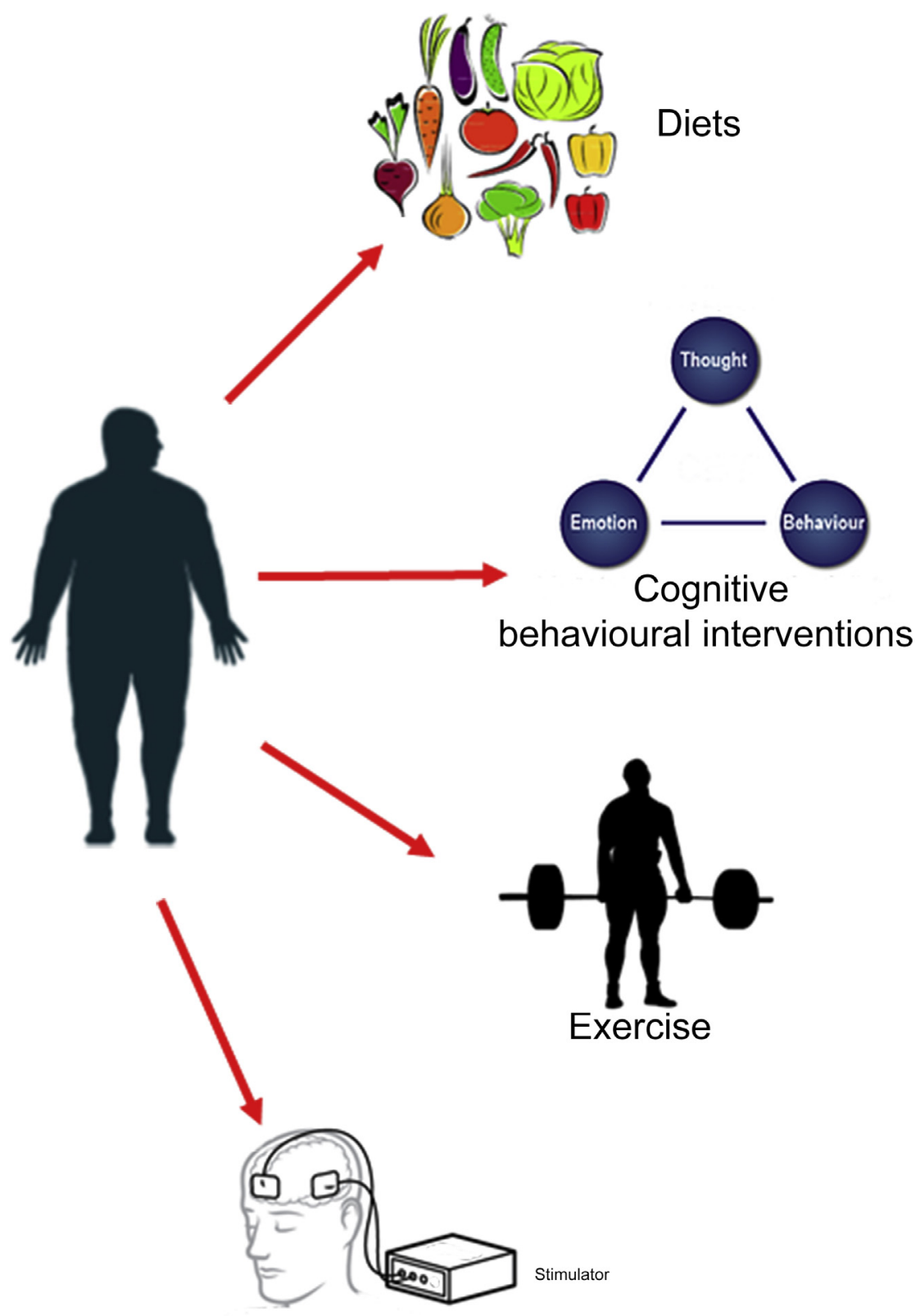

Transcranial direct current stimulation

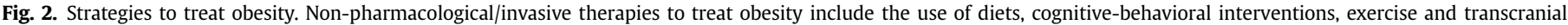

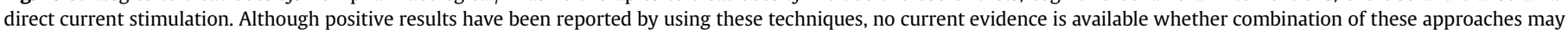
accelerate loss weight in obese patients than applying separately these interventions. 
developed aimed to manage and prevent this health issue. From approaches including drugs or surgical procedures, obesity has become one serious health problem in modern society that needs to be addressed with urgent [18,87-91]. However, obesity has become a complex health problem since multiple elements participate in the onset of this disease. Here, we highlighted the use of non-pharmacological/invasive techniques used to manage obesity, such as diets, cognitive behavioral intervention, exercise and transcranial direct current stimulation (Fig. 2).

Despite the positive outcomes of using these interventions have been reported, no solid evidence is available whether combination of these techniques may allow loss weight in obese patients in a more effective fashion than applying by separate these interventions. Thus, further evidence is needed to address this concern.

\section{Conflict of interest}

The authors declare no conflict of interest.

\section{Appendix A. Supplementary data}

Supplementary data related to this article can be found at https://doi.org/10.1016/j.clnesp.2018.04.005.

\section{References}

[1] WHO. Obesity and overweight. WHO; 2012.

[2] Hruby A, Hu FB. The epidemiology of obesity: a big picture. Pharmacoeconomics 2015;33:673-89. https://doi.org/10.1007/s40273-014-0243-X.

[3] Smith CJ, Ryckman KK. Epigenetic and developmental influences on the risk of obesity, diabetes, and metabolic syndrome. Diabetes Metab Syndrome Obes Targets Ther 2015;8:295-302. https://doi.org/10.2147/DMSO.S61296.

[4] Samaras T, Elrick H. An alternative hypothesis to the obesity epidemic: obesity is due to increased maternal body size, birth size, growth rate, and height Med Hypotheses 2005;65:676-82. https://doi.org/10.1016/j.mehy.2005.05. 015.

[5] Crönlein T. Insomnia and obesity. Curr Opin Psychiatr 2016:29:409-12.

[6] Liu W, Wang H, Wang Y, Li H, Ji L. Metabolic factors-triggered inflammatory response drives antidepressant effects of exercise in CUMS rats. Psychiatr Res 2015;228:257-64.

[7] Tan X, Alen M, Wiklund P, Partinen M, Cheng S. Effects of aerobic exercise on home-based sleep among overweight and obese men with chronic insomnia symptoms: a randomized controlled trial. Sleep Med 2016;25:113-21. https://doi.org/10.1016/j.sleep.2016.02.010.

[8] Kachur S, Lavie CJ, de Schutter A, Milani RV, Ventura HO. Obesity and cardiovascular diseases. Minerva Med 2017;108:212-28. https://doi.org/ 10.23736/S0026-4806.17.05022-4.

[9] Khan TA, Sievenpiper JL. Controversies about sugars: results from systematic reviews and meta-analyses on obesity, cardiometabolic disease and diabetes. Eur J Nutr 2016;55:25-43. https://doi.org/10.1007/s00394-016-1345-3.

[10] Kimbro RT, Sharp G, Denney JT. Home and away: area socioeconomic disadvantage and obesity risk. Health Place 2017;44:94-102. https://doi.org/ 10.1016/j.healthplace.2017.02.001.

[11] Huang F, Del-Rio-Navarro BE, Torres-Alcantara S, Perez-Ontiveros JA, RuizBedolla E, Saucedo-Ramirez OJ, et al. Adipokines, asymmetrical dimethylarginine, and pulmonary function in adolescents with asthma and obesity. J Asthma 2017;54:153-61. https://doi.org/10.1080/02770903.2016.1200611.

[12] McPherson AC, Hamilton J, Kingsnorth S, Knibbe TJ, Peters M, Swift JA et al. Communicating with children and families about obesity and weight-related topics: a scoping review of best practices. Obes Rev 2017;18:164-82. https:// doi.org/10.1111/obr.12485.

[13] Ehrlich AC, Friedenberg FK. Genetic associations of obesity: the fat-mass and obesity-associated (FTO) gene. Clin Transl Gastroenterol 2016;7:e140. https:// doi.org/10.1038/ctg.2016.1.

[14] Darbre PD. Endocrine disruptors and obesity. Curr Obes Rep 2017;6:18-27. https://doi.org/10.1007/s13679-017-0240-4.

[15] Patterson E, Ryan PM, Cryan JF, Dinan TG, Ross RP, Fitzgerald GF, et al. Gut microbiota, obesity and diabetes. Postgrad Med J 2016;92:286-300. https:// doi.org/10.1136/postgradmedj-2015-133285.

[16] Bouter KE, van Raalte DH, Groen AK, Nieuwdorp M. Role of the gut microbiome in the pathogenesis of obesity and obesity-related metabolic dysfunction. Gastroenterology 2017;152:1671-8. https://doi.org/10.1053/ j.gastro.2016.12.048.

[17] Janssen AW, Houben T, Katiraei S, Dijk W, Boutens L, van der Bolt N, et al. Modulation of the gut microbiota impacts non-alcoholic fatty liver disease: a potential role for bile acids. J Lipid Res 2017. https://doi.org/10.1194/ jlr.M075713.

[18] Heymsfield SB, Wadden TA. Mechanisms, pathophysiology, and management of obesity. N Engl J Med 2017;376:1492. https://doi.org/10.1056/ NEJMc1701944.

[19] Igel LI, Kumar RB, Saunders KH, Aronne LJ. Practical use of pharmacotherapy for obesity. Gastroenterology 2017;152:1765-79. https://doi.org/10.1053/ j.gastro.2016.12.049.

[20] Murphy JE. The addition of Visken to methyldopa therapy in hypertension: a multicentre study. J Int Med Res 1976;4:128-31. https://doi.org/10.1177/ 030006057600400209.

[21] Jordan J, Boye SW, Breton S Le, Keefe DL, Engeli S, Prescott MF. Antihypertensive treatment in patients with class 3 obesity. Ther Adv Endocrinol Metab 2012;3:93-8. https://doi.org/10.1177/2042018812445573.

[22] Jensen MD, Ryan DH, Apovian CM, Ard JD, Comuzzie AG, Donato KA, et al. 2013 AHA/ACC/TOS guideline for the management of overweight and obesity in adults: a report of the American College of Cardiology/American Heart Association Task Force on practice guidelines and the obesity society. Circulation 2014;129:S102-38. https://doi.org/10.1161/01.cir.0000437739. 71477.ee.

[23] Banack HR, Kaufman JS. The obesity paradox: understanding the effect of obesity on mortality among individuals with cardiovascular disease. Prev Med (Baltim) 2014;62:96-102. https://doi.org/10.1016/j.ypmed.2014.02.003.

[24] Berrington de Gonzalez A, Hartge P, Cerhan JR, Flint AJ, Hannan L, MacInnis RJ, et al. Body-mass index and mortality among 1.46 million white adults. $\mathrm{N}$ Engl J Med 2010;363:2211-9. https://doi.org/10.1056/NEJMoa1000367.

[25] Martin CK, Gadde KM. Weight loss: slow and steady does not win the race. Lancet Diabetes Endocrinol 2014;2:927-8.

[26] Asghari G, Mirmiran P, Yuzbashian E, Azizi F. A systematic review of diet quality indices in relation to obesity. Br J Nutr 2017:1-11.

[27] Lichtenstein AH, Carson JS, Johnson RK, Kris-Etherton PM, Pappas A, Rupp L et al. Food-intake patterns assessed by using front-of-pack labeling program criteria associated with better diet quality and lower cardiometabolic risk. An J Clin Nutr 2014:99:454-62.

[28] Yeh JS, Kushner RF, Schiff GD. Obesity and management of weight loss. N Engl J Med 2016;375:1187-9. https://doi.org/10.1056/NEJMclde1515935.

[29] Moosavi F, Hosseini R, Saso L, Firuzi O. Modulation of neurotrophic signaling pathways by polyphenols. Drug Des Dev Ther 2016;10:23-42. https://doi.org/ 10.2147/DDDT.S96936.

[30] Noratto G, Chew BP, Ivanov I. Red raspberry decreases heart biomarkers of cardiac remodeling associated with oxidative and inflammatory stress in obese diabetic db/db mice. Food Funct 2016;7:4944-55. https://doi.org/ 10.1039/c6fo01330a.

[31] Amiot MJ, Riva C, Vinet A. Effects of dietary polyphenols on metabolic syndrome features in humans: a systematic review. Obes Rev 2016;17:573-86 https://doi.org/10.1111/obr.12409.

[32] Curioni CC, Lourenco PM. Long-term weight loss after diet and exercise: a systematic review. Int J Obes 2005:29:1168-74.

[33] Rabkin SW, Campbell H. Comparison of reducing epicardial fat by exercise diet or bariatric surgery weight loss strategies: a systematic review and metaanalysis. Obes Rev 2015;16:406-15.

[34] Hamilton K, Thomson CE, White KM. Promoting active lifestyles in young children: investigating mothers' decisions about their child's physical activity and screen time behaviours. Matern Child Health J 2013;17:968-76.

[35] Spinks T, Hamilton K. Investigating key beliefs guiding mothers' dietary decisions for their 2-3 year old. Appetite 2015;89:167-74.

[36] Jacobs DR, Tapsell LC. Food, not nutrients, is the fundamental unit in nutrition. Nutr Rev 2007;65:439-50.

[37] Ajzen I. The theory of planned behaviour: reactions and reflections. 2011.

[38] McDermott MS, Oliver M, Svenson A, Simnadis T, Beck EJ, Coltman T, et al. The theory of planned behaviour and discrete food choices: a systematic review and meta-analysis. Int J Behav Nutr Phys Activ 2015;12:162.

[39] Beauchamp MR. Myths, presumptions, and facts about obesity. N Engl J Med 2013;368:2235-6. https://doi.org/10.1056/NEJMc1303009\#SA3.

[40] Passos GS, Poyares DLR, Santana MG, Tufik S, de Mello MT. Is exercise an alternative treatment for chronic insomnia? Clinics 2012;67:653-60.

[41] Budde H, Schwarz R, Velasques B, Ribeiro P, Holzweg M, Machado S, et al. The need for differentiating between exercise, physical activity, and training. Autoimmun Rev 2016;15:110-1. https://doi.org/10.1016/j.autrev.2015.09.004.

[42] Howley ET. Type of activity: resistance, aerobic and leisure versus occupational physical activity. Med Sci Sports Exerc 2001;33. S364-9-20.

[43] Blair SN, Kohl HW, Powell KE. Physical activity, physical fitness, exercise, and the public's health. Acad Pap 1987;20:53-69.

[44] Caspersen CJ, Powell KE, Christenson GM. Physical activity, exercise, and physical fitness: definitions and distinctions for health-related research. Pub Health Rep 1985;100:126.

[45] Trumbo P, Schlicker S, Yates AA, Poos M. Dietary reference intakes for energy carbohydrate, fiber, fat, fatty acids, cholesterol, protein and amino acids. J Am Diet Assoc 2002;102:1621-30.

[46] Garber CE, Blissmer B, Deschenes MR, Franklin BA, Lamonte MJ, Lee I-M, et al. American College of Sports Medicine position stand. Quantity and quality of exercise for developing and maintaining cardiorespiratory, musculoskeletal, and neuromotor fitness in apparently healthy adults: guidance for prescribing exercise. Med Sci Sports Exerc 2011;43:1334-59. https://doi.org/10.1249/ MSS.0b013e318213fefb. 
[47] Houmard JA, Pories WJ, Dohm GL. Is there a metabolic program in the skeletal muscle of obese individuals? J Obes 2011;2011.

[48] Goedecke JH, Micklesfield LK. The effect of exercise on obesity, body fat distribution and risk for type 2 diabetes. Diabetes Phys Act 2014;60:82-93. Karger Publishers.

[49] Pérusse L, Collier G, Gagnon J, Leon AS, Rao DC, Skinner JS, et al. Acute and chronic effects of exercise on leptin levels in humans. J Appl Physiol 1997;83: 5-10.

[50] Foster-Schubert KE, McTiernan A, Frayo RS, Schwartz RS, Rajan KB, Yasui Y, et al. Human plasma ghrelin levels increase during a one-year exercise program. J Clin Endocrinol Metab 2005;90:820-5.

[51] Cummings DE, Weigle DS, Frayo RS, Breen PA, Ma MK, Dellinger EP, et al. Plasma ghrelin levels after diet-induced weight loss or gastric bypass surgery. N Engl J Med 2002;346:1623-30.

[52] Hansen TK, Dall R, Hosoda H, Kojima M, Kangawa K, Christiansen JS, et al. Weight loss increases circulating levels of ghrelin in human obesity. Clin Endocrinol (Oxf) 2002;56:203-6.

[53] Lejeune M, Hukshorn CJ, Saris WHM, Westerterp-Plantenga MS. Effect of dietary restraint during and following pegylated recombinant leptin (PEG-OB) treatment of overweight men. Int J Obes 2003;27:1494-9.

[54] Mason C, Xiao L, Imayama I, Duggan CR, Campbell KL, Kong A, et al. The effects of separate and combined dietary weight loss and exercise on fasting ghrelin concentrations in overweight and obese women: a randomized controlled trial. Clin Endocrinol (Oxf) 2015;82:369-76.

[55] Strohacker K, McCaffery JM, Maclean PS, Wing RR. Adaptations of leptin, ghrelin or insulin during weight loss as predictors of weight regain: a review of current literature. Int J Obes 2014;38:388-96.

[56] Iwayama K, Kurihara R, Nabekura Y, Kawabuchi R, Park I, Kobayashi M, et al. Exercise increases 24-h fat oxidation only when it is performed before breakfast. EBioMedicine 2015;2:2003-9.

[57] Sasaki H, Hattori Y, Ikeda Y, Kamagata M, Shibata S. Eating meals before wheel-running exercise attenuate high fat diet-driven obesity in mice under two meals per day schedule. Chronobiol Int 2015;32:677-86.

[58] Jakicic JM, Marcus BH, Gallagher KI, Napolitano M, Lang W. Effect of exercise duration and intensity on weight loss in overweight, sedentary women: a randomized trial. J Am Med Assoc 2003;290:1323-30. https://doi.org/ 10.1001/jama.290.10.1323.

[59] Sukala WR, Page R, Lonsdale C, Lys I, Rowlands D, Krebs J, et al. Exercise improves quality of life in indigenous Polynesian peoples with type 2 diabetes and visceral obesity. J Phys Activ Heal 2013;10:699-707.

[60] Abdelaal AAM, Mohamad MA. Obesity indices and haemodynamic response to exercise in obese diabetic hypertensive patients: randomized controlled trial. Obes Res Clin Pract 2015;9:475-86.

[61] Decker ES, Ekkekakis P. More efficient, perhaps, but at what price? Pleasure and enjoyment responses to high-intensity interval exercise in low-active women with obesity. Psychol Sport Exerc 2017;28:1-10.

[62] Vainik U, Dagher A, Dubé L, Fellows LK. Neurobehavioural correlates of body mass index and eating behaviours in adults: a systematic review. Neurosci Biobehav Rev 2013;37:279-99.

[63] Carnell S, Gibson C, Benson L, Ochner CN, Geliebter A. Neuroimaging and obesity: current knowledge and future directions. Obes Rev 2012:13:43-56.

[64] Brooks SJ, Cedernaes J, Schiöth HB. Increased prefrontal and parahippocampal activation with reduced dorsolateral prefrontal and insular cortex activation to food images in obesity: a meta-analysis of fMRI studies. PLoS One 2013;8: e60393.

[65] Kringelbach ML, de Araujo IET, Rolls ET. Taste-related activity in the human dorsolateral prefrontal cortex. Neuroimage 2004;21:781-8.

[66] Gautier J-F, Chen K, Salbe AD, Bandy D, Pratley RE, Heiman M, et al. Differential brain responses to satiation in obese and lean men. Diabetes 2000;49: 838-46.

[67] Gautier J, Parigi A, Chen K, Salbe AD, Bandy D, Pratley RE, et al. Effect of satiation on brain activity in obese and lean women. Obesity 2001:9:676-84.

[68] Tataranni PA, Gautier J-F, Chen K, Uecker A, Bandy D, Salbe AD, et al. Neuroanatomical correlates of hunger and satiation in humans using positron emission tomography. Proc Natl Acad Sci 1999:96:4569-74.

[69] DelParigi A, Chen K, Salbe AD, Hill JO, Wing RR, Reiman EM, et al. Persistence of abnormal neural responses to a meal in postobese individuals. Int J Obes 2004;28:370-7.
[70] Le DSNT, Pannacciulli N, Chen K, Del Parigi A, Salbe AD, Reiman EM, et al. Less activation of the left dorsolateral prefrontal cortex in response to a meal: a feature of obesity. Am J Clin Nutr 2006;84:725-31.

[71] Le DSNT, Chen K, Pannacciulli N, Gluck M, Reiman EM, Krakoff J. Reanalysis of the obesity-related attenuation in the left dorsolateral prefrontal cortex response to a satiating meal using gyral regions-of-interest. J Am Coll Nutr 2009;28:667-73.

[72] Le DSNT, Pannacciulli N, Chen K, Salbe AD, Hill JO, Wing RR, et al. Less activation in the left dorsolateral prefrontal cortex in the reanalysis of the response to a meal in obese than in lean women and its association with successful weight loss. Am J Clin Nutr 2007;86:573-9.

[73] Fabricatore AN, Wadden TA. Obesity. Annu Rev Clin Psychol 2006;2:357-77. https://doi.org/10.1146/annurev.clinpsy.2.022305.095249.

[74] Nitsche MA, Cohen LG, Wassermann EM, Priori A, Lang N, Antal A, et al. Transcranial direct current stimulation: state of the art 2008. Brain Stimul 2008;1:206-23.

[75] Wassermann EM, Grafman J. Recharging cognition with DC brain polarization. Trends Cognit Sci 2005;9:503-5.

[76] Wassermann EM. Direct current brain. Oxford Handb Transcranial Stimul 2008:57.

[77] Val-Laillet D, Aarts E, Weber B, Ferrari M, Quaresima V, Stoeckel LE, et al. Neuroimaging and neuromodulation approaches to study eating behavior and prevent and treat eating disorders and obesity. Neurolmage Clin 2015;8: $1-31$.

[78] Kekic M, McClelland J, Campbell I, Nestler S, Rubia K, David AS, et al. The effects of prefrontal cortex transcranial direct current stimulation (tDCS) on food craving and temporal discounting in women with frequent food cravings. Appetite 2014;78:55-62.

[79] Goldman RL, Borckardt JJ, Frohman HA, O'Neil PM, Madan A, Campbell LK, et al. Prefrontal cortex transcranial direct current stimulation (tDCS) temporarily reduces food cravings and increases the self-reported ability to resist food in adults with frequent food craving. Appetite 2011;56:741-6.

[80] Fregni F, Orsati F, Pedrosa W, Fecteau S, Tome FAM, Nitsche MA, et al. Transcranial direct current stimulation of the prefrontal cortex modulates the desire for specific foods. Appetite 2008;51:34-41.

[81] Jauch-Chara K, Kistenmacher A, Herzog N, Schwarz M, Schweiger U, Oltmanns KM. Repetitive electric brain stimulation reduces food intake in humans. Am J Clin Nutr 2014;100:1003-9.

[82] Lapenta OM, Di Sierve K, de Macedo EC, Fregni F, Boggio PS. Transcranial direct current stimulation modulates ERP-indexed inhibitory control and reduces food consumption. Appetite 2014;83:42-8.

[83] Montenegro RA, Okano AH, Cunha FA, Gurgel JL, Fontes EB, Farinatti PTV. Prefrontal cortex transcranial direct current stimulation associated with aerobic exercise change aspects of appetite sensation in overweight adults. Appetite 2012;58:333-8.

[84] Gluck ME, Alonso-Alonso M, Piaggi P, Weise CM, Jumpertz-von Schwartzenberg R, Reinhardt M, et al. Neuromodulation targeted to the prefrontal cortex induces changes in energy intake and weight loss in obesity. Obesity 2015;23:2149-56.

[85] Ljubisavljevic M, Maxood K, Bjekic J, Oommen J, Nagelkerke N. Long-term effects of repeated prefrontal cortex transcranial direct current stimulation (tDCS) on food craving in normal and overweight young adults. Brain Stimul 2016;9:826-33.

[86] Halpern CH, Torres N, Hurtig HI, Wolf JA, Stephen J, Oh MY, et al. Expanding applications of deep brain stimulation: a potential therapeutic role in obesity and addiction management. Acta Neurochir (Wien) 2011;153:2293-306.

[87] Narayanaswami V, Dwoskin LP. Obesity: current and potential pharmacotherapeutics and targets. Pharmacol Ther 2017;170:116-47.

[88] Umashanker D, Igel LI, Kumar RB, Aronne LJ. Current and future medical treatment of obesity. Gastrointest Endosc Clin N Am 2017;27:181-90.

[89] Serhan CN. Treating inflammation and infection in the 21st century: new hints from decoding resolution mediators and mechanisms. FASEB J 2017;31: 1273-88.

[90] Jeremic N, Chaturvedi P, Tyagi SC. Browning of white fat: novel insight into factors, mechanisms, and therapeutics. J Cell Physiol 2017;232:61-8.

[91] Meldrum DR, Morris MA, Gambone JC. Obesity pandemic: causes, consequences, and solutions-but do we have the will? Fertil Steril 2017;107: 833-9. 